\title{
The possibility of achievement of the nZEB state of a refurbished detached house powered solely by renewable energy sources in Southern Poland
}

\author{
Jacek Biskupski ${ }^{1, *}$ \\ ${ }^{1}$ AGH University of Science and Technology, Dep. of Energy and Fuels, Al. Adama Mickiewicza 30, PL- 30-059 Cracow, Poland
}

\begin{abstract}
This paper gives a thorough description of the two different scenarios of retrofit of an existing detached country house (with high primary energy demand) to a net zero energy building (nZEB) or near zero energy (nearZEB) by using energy form on-site RES. Using a designed piece of modelling software author pointed out two possible solutions. First one, based on a bio boiler and small on-site PV generator (on-grid) and the other based on large PV generator and three heat pumps. A 24 months test was performed in order to find out the output of both scenarios. In first period, the bio boiler delivered energy for space heating and DHW, while energy from PV was used to cover all electricity needs of the household during the 12 months testing period. In the later, the energy received from 10 $\mathrm{kWp}$ PV of was partly used to cover the current needs of the entire household (switchable on/off-grid system), and surplus was stored in the national electricity grid and regained later in the winter for the space heating (by a GSHP) and ventilation (ASHP) and DHW (dedicated ASHP). In both cases the system proofed the possibility to achieve the nZEB (nearZEB in first scenario) state of the household, as all (in the first near all) energy needs were covered by renewable energy produced on-site.
\end{abstract}

\section{Preface}

The EU Directives and guidelines, (especially EPBD), stats clear that all new buildings in Europe shall be nearly or net Zero Energy Buildings (nZEB) from 2020 onwards. The exact definition of nZEB and nearZEB are to be developed by members states of EU, but general definition describing them as "buildings with very low energy demand, covered mostly by energy from RES harnessed locally" which could be used in both cases. In Poland the netZEB is understand as state of zero nett energy building (in polish "nZEB"), where the amount of entire energy delivered to the boundary is equal the entire energy used by entire household. The definition of nearZEB (in polish "niemalZEB") is a case of a building with yearly energy demand approaching the state where all energy needs [2] are reduced beyond the state minimum demand $(95 \mathrm{kWh} / \mathrm{m} 2$ year as per year 2017).

In Poland there are $\sim 4$ million existing houses and at least 150.000 new ones are raised every year [1]. The vast majority $(>85 \%)$ of existing detached buildings use coal and natural gas to deliver energy for space heating and DHW. Some of new building go for bio-boilers (mainly wooden pellets) and heat pumps. The PV systems are at the initial stage but getting wind [4]. From the year 2016 polish prosumerism started, as new bill on net metering for PV weas introduced [3]. According to this regulation, every household in Poland is entitled to install a on-grid PV generator (up to $40 \mathrm{kWp}$ ), and grid company is forced to intake the surplus of produced insite energy without any constrains. As it is net-metering model, the grid company has to give it back to the household in a period of a year (with a $20 \%$ deduction volume charge) so it is net metering rated 1:0,8 instead of 1:1. It means once one household transfers to the grid $10 \mathrm{MWh}$ in summer, is entitled to get back $8 \mathrm{MWh}$ into the end of the 365 days period.. Not collected (in 365 days) energy surplus is not transferable, neither returned back in any form. In practise $10 \mathrm{MWh}$ transfered to the grid and redeemed by household only $6 \mathrm{MWh}$ means 2 MWh given out to the grid company for free (as the 20 $\%$ werer gained by the grid as their "fee"). Despite this, the amount of individual PV installations in Poland doubles every year [4]. Poland has quite a good solar radiation, similar to one in Germany, even better to the GB's one. PV systems are relatively cheap, partly manufactured locally and most of suppliers give for them longer warranty than for example ST panels. Poland is gaining momentum with PV solar Energy.

The roof top PV generator seems to be the cheapest and most reliable solution in a way to receive sustainable energy to create a nZEB household in Poland. The problem is, that generally polish detached houses have space heating and DHW systems based on coal/natural gas boilers with relatively high demand for the final energy (only $11 \%$ of houses have less than 150 $\mathrm{kWh} / \mathrm{m} 2$ year[1]) at high heating medium temperatures. In order to meet such a high demand, the PV roof top

Corresponding author: jacek.biskupski181@gmail.com 
systems are not able to deliver sufficient amount of energy (simply the roofs are too small and efficiency too low to harness desired amount of electric energy). On the other hand, there is lot of bio fuels available in Poland. The wood chips as well as pellets are widely manufactured here (Poland is one of important exporters of bio fuels in EU). There are some researchers opting for oats as potential bio fuel [2] as we had long history of planting oats. Historians claim that before World War II, there were over one million hectares planted oats, reduced to some 200 thousand nowadays. There are other RES potentials like heat pumps (also manufactured locally), which already gained wide acceptance. Author seeks for sets of reliable solutions for retrofitting polish typical detached households to a nZEB houses.

\section{Potential solutions considered}

Author has considered many heating systems solutions as a potential retrofit of an existing detached house into a nZEB where HVAC system is currently powered by a coal/natural gas boiler. In the research we have focused on detached and semi-detached houses, claiming that MFH creates completely different challenges. First observation lead to a differentiation related to actual positioning of the building and its urbanistic relation to the environment. Table 1 shows this consideration.

Table 1. Potential retrofit solutions toward nZEB of existing detached house depending on location.

\begin{tabular}{|c|c|c|c|c|}
\hline $\begin{array}{c}\text { Main } \\
\text { source of } \\
\text { energy }\end{array}$ & City & Suburb & Village & $\begin{array}{c}\text { Env. } \\
\text { Impact }\end{array}$ \\
\hline Natural gas & + & $+*$ & $+*$ & Modereate \\
\hline Bio & - & $+* *$ & + & Low \\
\hline $\begin{array}{c}\text { Heat Pump } \\
\text { PV (as DC } \\
\text { heat } \\
\text { source) }\end{array}$ & $+*$ & $+*$ & + & $\begin{array}{c}\text { Modereate } \\
\text { /Low }\end{array}$ \\
\hline LPG & - & + & + & Modereate \\
\hline
\end{tabular}

Source: Author's PHD research [2]

* - where available/possible, not every location has the potential to install it.

** - solid state powered boilers are currently banned in many polish cities and some city suburbs has also this restriction.

Data in Table 1 [2] shows some limitations in wide use of solid fuels boilers and boilers nationwide. Due to high level of pollutions in Poland, there are many places where a total ban on solid fuels was introduced including bio pellets (eg. city of Cracow). Worth to quote here, that in a list of 50 the most polluted cities in EU, as many as 30 are located in Poland. Natural gas is not accessible everywhere (due to lack of the piping) and the LNG containers are so far too expensive for detached households, so far. The oil and LPG are not considered as potential eco-retrofit, mainly due to high prices of installation and questionable environmental impact. Environmentally speaking, in comparison of the natural gas and coal, the coal burning (in-site) always brings carbon dioxide and some pollutions (sometimes causing smog), while natural gas brings "only" carbon dioxide and water vapor. This become vital when cost of carbon dioxide emissions, are taken in account. Many bio boilers may bring significant emissions with practically very low carbon dioxide emission (the fuel is considered to be planted locally). On the other hand, the local bans do not allow to use them (bio boilers/stoves) widely for retrofit.

Heat pumps (ASHP and GSHP) are very promising, but they still show demand for lot of primary energy (Poland's in European cold climate area). Especially in Poland any electricity based heating system cause a problem in achieving limits of primary energy per house, as primary energy coefficient electricity for electricity is very high $(\mathrm{CC}=3)$. Only HP's with high performance of SCOPnet $=>3,5$ are suitable here. PV as main source of energy - in Poland - has the main disadvantage of sesonal harvesting, eg $80 \%$ of energy coming in summer period, when most of the energy needs comes in winter heating season. Thus direct PV DC heating (be electric DC heaters) seems to be not suitable as the main heating system of the house. Very interesting solution lays potentially in PV generation (as renewable primary energy source) and use it as main source of energy for heat pumps. From the environmental impact point of view such a solution could be assigned as "Moderate" when the grid energy is used to run a HP, or "Low" when the on-site PV energy is used to power a compressor and shunt pumps in a HP. Comparing to grid electricity, Author come to conclusion, that PV energizing HP seems to be the most suitable solution for nZEB. Such a solution use minimum of primary energy and generates minimum pollution in LC. Also bio fuels planted locally, like wood chops and oats could potentially demand lowest amount of primary energy, especially the derived from fossil fuels. The biggest disadvantage of the such a natural bio harvesting seemed to be the amount of human work demanded from the residents or the neighbours. As far as PV is concern, the $\mathrm{PV}$ generators working together with the grid as storage media, seemed to be very attractive - even with the cost of $20-30 \%$ (depending on nominal ower of PV generator). The first result from this research was, that in Poland the bio and PV with HP's are potentially the best solutions toward sustainable retrofit of and existing building toward a nZEB one (with some restrictions to the building's location). It's obvious that some improvements in house insulation as well as ventilation systems should be made first. For the insulation the certain level of heat loses of the building envelope must be achieved first, which is more important for HP's solution than for the bio boilers. Also the efficiency and accuracy of ventilation system seemed to be very important factor from the very beginning of planning. First modelling results showed clearly, that natural (gavity driven) ventilation system generates too much 
energy loses to be suitable for nZEB or even is too difficult for nearZEB. Also in both Variants (1 and 2) the retrofit house ventilation to a mechanical system with heat high efficiency heat recovery were designed.

\section{Methodolgy and Results}

\subsection{Applied Solutions}

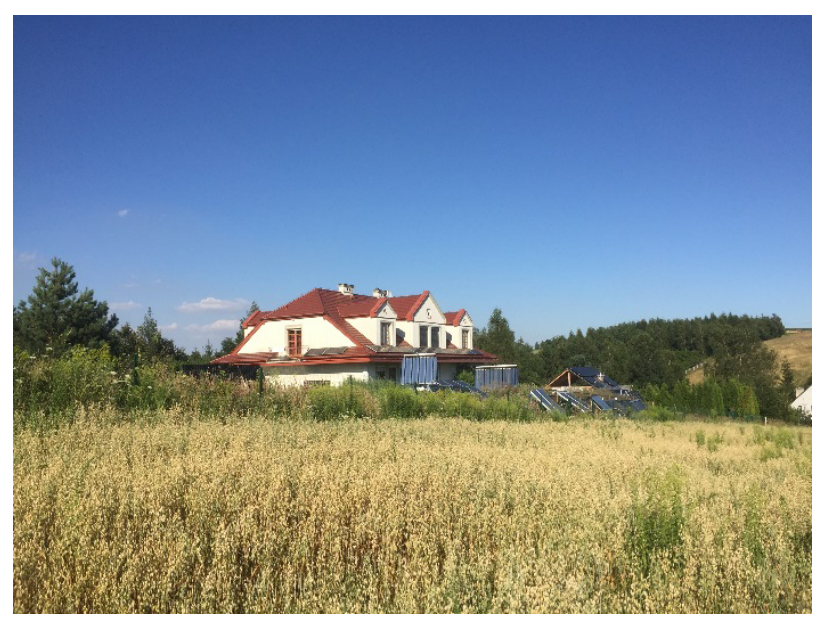

Fig. 1. The test building surrounded by oats fields and PV/ST panels used as proposed in the first retrofit scenario.

\subsubsection{The bio boiler as main source of energy for HVAC system}

The country house, located south of Poland (near Cracow), inhabited with a eco orientated family of 4 people was the laboratory. The idea of applying a bio boiler was the first to come for house like this, showing very high oats planting potential around. At the first stage Author decided [2] to retrofit in this house (a natural gas combustion boiler $(24 \mathrm{~kW})$ to a new, $30 \mathrm{~kW}$ bio boiler (class 5) powered by pellet or oats as a fuel (switchable). At first stage of experiment (from 03.05.2016 till 02.05.2017) the local manufactured boiler was the main source of space heating, using this same house distribution heat system as previously with the gas boiler (heat exchanger and radiators). Also DHW system stayed unchanged, still powered from the main space heating boiler (also heated in summer from PV-ST). The auxiliary energy demand as well as home appliances were retrofit to be powered solely from 4,5 PV generator connected on/off-grid (switchable by BMS). BMS system was redesigned to handle the new HVAC management.

\subsubsection{Heat Pumps as main source of heat and cool and energy for DHW}

In the second stage of experiment (from 03.05.2017 till 02.05.2018) the bio boiler was turned off and three heat pumps were deployed to deliver space heating (GSHP 14kW), ventilation and cooling (ASHP 3,5kW) and DHW preparation (ASHP $3 \mathrm{~kW}$ ). This solution for
nZEB building was already recommend in European Standard [4]. Worth to mention, that the HP's ground exchanger was placed just below the oats filed (the oats was still planted but not used as a fuel).

\subsubsection{Photovoltaic generator in the house}

The all house appliances were turned to electricity and taken in account in energy demand calculation (counted as auxiliary energy incl. shunt pumps, lights, ITC units). In order to power it all, the first variant roof top PV generator of $4,5 \mathrm{kWp}$ was redesigned and repowered with new PV modules. In the stage the PV generator was enlarged using some extra space (like roof of the garage and a piece of the surrounding ground) at the south side of the house (Fig 2). Finally, the on-site PV generator was enlarged to the potential of $10 \mathrm{kWp}$ delivering some $10 \mathrm{MWh}$ yearly. The energy was partly used by the house appliances directly (DC and AC via inverters) and partly exported (mainly in the summer) to the grid and consequently redeemed in the winter.

\section{The theoretic base}

The theoretical base for the yearly energy calculation for such a solution is drawn in a formula [1] proposed by the Author.

$$
U * \int_{A}(P \operatorname{Supp}(t)-\operatorname{PDem}(t)) d t+\int_{R \backslash A}(\operatorname{PDem}(t)-\operatorname{PSupp}(t)) d t=0(1)
$$

where: PSupp - is stream of energy delivered to the household from RES (single carrier), PDem- is the total energy demand of household, $U=1 /$ Es, where Es is efficiency coefficient of the energy storage, in Poland it is currently equal to 0,8 or 0,7 (for PV installations up to $10 \mathrm{kWp}$ and above $10 \mathrm{kWp}$ respectively). The idea was first introduced in [2], similar to work in [6].

At the first stage of experiment, the space heating and DHW was calculated separately as it was covered by the energy from bio boiler and partially from existing ST. The electricity demand was covered partly by on-site PV. The PV energy was (in every hour of the year) instantly used by the household devices to maximum possible level and surplus "exported" to the grid (managed by the BMS). The two like (1) equitation's were used (one for heat and the other for electricity). In the second scenario, (heat pumps) yearly energy demand of the entire household was converted to electricity and calculated according to equitation (1) as received from RES.

The idea of net zero energy demand of the entire household is based on comparison of input stream of energy from RES and output energy (demand and supply) during the course of a year, taking on account the storage of energy surplus in the grid Es (1). The initial calculation of electricity demand (in the first scenario) showed that $4.5 \mathrm{kWp} \mathrm{PV}$ generator should be able to deliver desired electricity in this house, excluding 
the space heating (bio boiler fueled by oats) and cooling (not existed in the first scenario). For the other scenario (Variant 2) the modeling showed, that using designed HP's the energy harnessed In the other scenario, modelling software based on (1) showed that the RES system should be enlarged to $10 \mathrm{kWp}$.

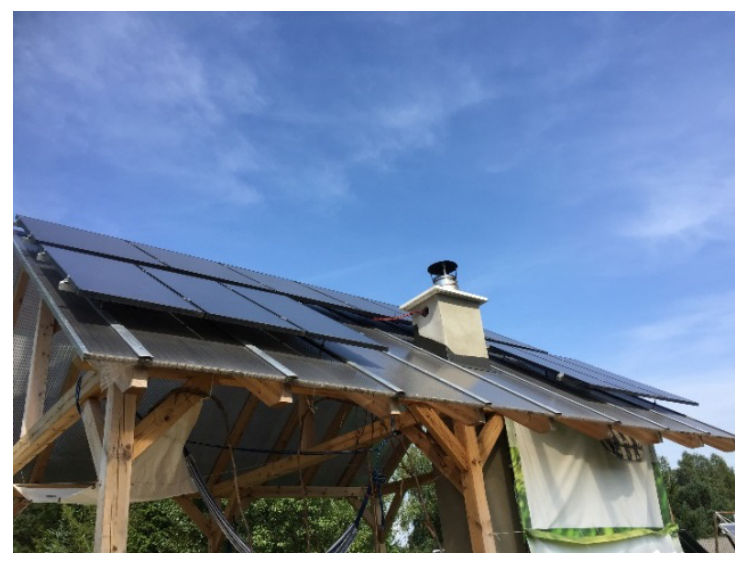

Fig. 2. An extra PV panels deployed in the second scenario at the roof top of a garage.

\subsection{Building calculation modelling}

In order to establish the energy demand two steps modelling process was used

1) The software calculation of energy demand of the entire household (in silico)

2) The real energy consumption measurement performed in real time by the Unihome ${ }^{\circledR}$ BMS System (in situ) was compared to the calculated values.

3) The differences were reported and analysed on-line and discussed every month with the inhabitants.

In the first scenario (bio boiler $+4,5 \mathrm{kWp}$ PV) the total energy demand was calculated for $5 \mathrm{Mg}$ of bio fuel (sun dried oats at $18 \mathrm{MJ} / \mathrm{kg}$ ) and around $4500 \mathrm{kWh}$ combined (self use and some "accumulated" in the grid) electricity. In the second scenario around 8-10 MWh was calculated as enough to meet the yearly demand $(10 \mathrm{kWp}$ delivering $10 \mathrm{MWh}$ of electricity, and some energy given out to the grid system). The cooling part of PV (PVT) was used to preheat the DHW in most time of the "warmer seasons".

The test performed in 24 months aimed to compare the operational rating with the modelling calculations in two possible retrofit scenarios. In both cases Author expected energy balance effects closed to modelling measured by the real consuming of delivered energy, as the operational rating of the household was well known prior to the experiment (separately for space heating and DHW and for el. appliances - from individual meters). The energy performance as well as space comfort was measured every hour and discussed with residents periodically. The unknown part was in total emissions of GHG triggered by the retrofitted system, and the inhabitant's reaction to new challenges related to the new HVAC systems introduced. More about it in the chapter Troubleshooting.

\section{Discussion}

\subsection{The sun proved to be potentially the main source of energy for entire HVAC system}

The first performed scenario (bio+PV) proved to be closed to the modelling. Following the theoretical calculation, author expected some $5 \mathrm{Mg}$ of oats to be burned in the boiler and the energy from 4,5 kWp PV plus existing ST (PVT) would cover the total demand of energy (heat\&electricity) in a year. In real, due to problems with the existing leaks ventilation the boiler burned 5,8 Mg of oats in heating season. The demand for electricity was closed to the calculated modelling value of 4400-4600 kWh (+/- $100 \mathrm{kWh})$. Nevertheless, the building showed demand for more energy than calculated This gap was bridged mainly by thermal part of PVT panels and grid electricity, and went for ventilation and DHW. In order to limit the final demand, in the middle step, some modifications were made between phase one and two. First (before performing the second scenario), the air tightness of the building was tested and improved, fixing air leakage in attic area. Some windows which showed leaks, were also fixed. The domestic hot water system was completely redesigned getting rid of circullation. Some minor changes in management software (BMS) were made (eg better information system regarding the energy balance for every day of the year). The biggest change was in improving the HRS (energy recovery in ventilation system), and to existing HRS system an extra ground exchanger (gravel) was added. Finally, in the second part of the performed test (Variant 2), the building was more closed to the calculated data at modelling stage. The final generation of $9650 \mathrm{kWh}$ of electricity (including some heat from specially designed for the purpose PVT panels) was enough to meet the year demand of the entire household of 4 people and ensure the internal climate comfort during the whole year. The very important comfort up-grade in the second stage was new feature of climate control (low air temperature inflow), which brought a new level of comfort to this country house.

\subsection{The financial investment and LCC consideration}

In Table 2, there is a matrix of financial and environmental aspects of considered retrofits.

The financial investments (CAPEX) was widely discussed with the home owners, but not in the entry stage. In order to leave them not biased by the real investment costs, the test were performed using leased HVAC systems instead of purchased (fixed small rate per month). The final costs were shown to the residents after the 24 months period. At the stage of testing, the initial analyse was presented to them (described in Table 2 ). Due to high environmental responsibility of the entire "family to be tested" they preferred the second scenario from the very beginning, but also liked idea of planting fuels by themselves (oats). Finally, after 24 months test, 
they were deeply surprised by the real CAPEX of solutions (the second appeared to be much more expensive) but presented LCC was for them encouraging. The perspective of 15 years without any expenditure for HVAC and activity from their side was finally convincing. Additional surplus of potential planted oats (extra income from selling out the crop) become a main argument for the second solution. Despite tree fold higher cost of the hardware for the second scenario they went for the heat pumps solution. The bio boiler was dismounted after the test.

Table 2. Financial and environmental analyse.

\begin{tabular}{|c|c|c|c|c|}
\hline $\begin{array}{c}\text { Space } \\
\text { heat } \\
\text { +DHW }\end{array}$ & $\begin{array}{c}\text { Env.imp } \\
\text { act }\end{array}$ & $\begin{array}{c}\text { LCC } \\
\text { Cost }\end{array}$ & Capex & $\begin{array}{c}\text { Primary } \\
\text { energy } \\
\text { Consumption }\end{array}$ \\
\hline $\begin{array}{c}\text { Bio } \\
\text { boiler }\end{array}$ & Low & Low & Moderate & Acceptable \\
\hline $\begin{array}{c}\text { Gas } \\
\text { boiler }\end{array}$ & Moderate & High & Low & Too high \\
\hline Pv+HP & Low & Low & High & Acceptable \\
\hline PV + gas & Moderate & Moderate & Moderate & Acceptable \\
\hline
\end{tabular}

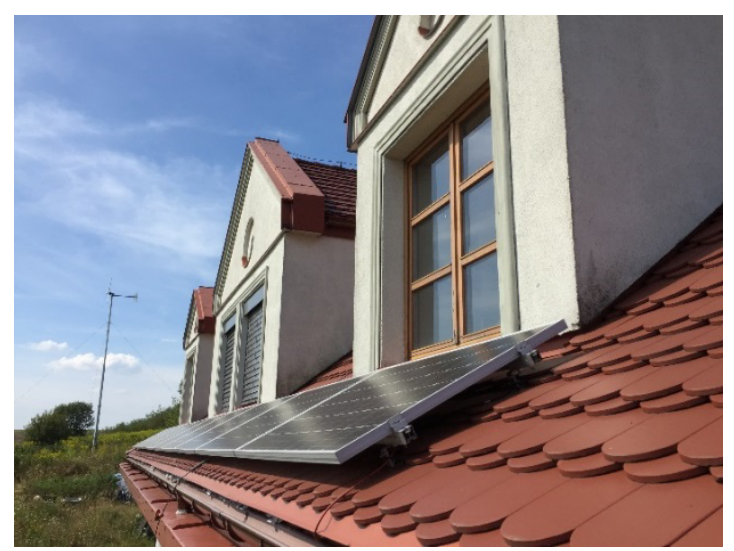

Fig 3. The house with PV mounted at the roof at the first stage of experiment.

\subsection{Troubleshooting}

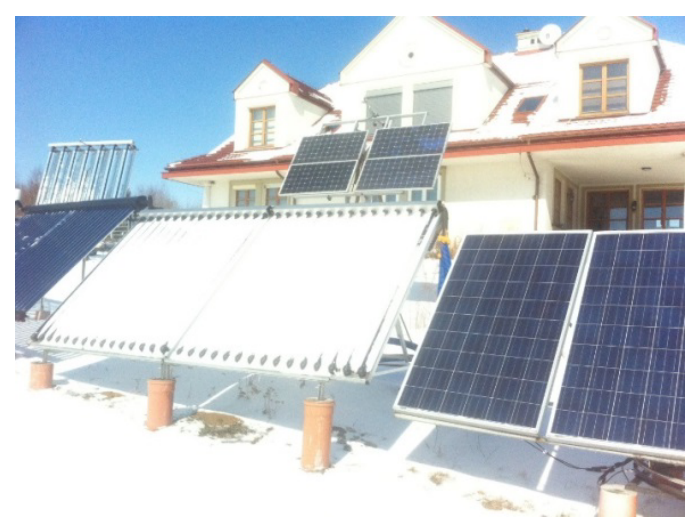

Fig 4. The ST and PV arrays in front the house in winter.

\subsubsection{The human factor}

As they had seemed to be excited at the beginning they were a bit confused at the end of first 12 months test.

The residents found that the main disadvantage of the first scenario was - unexpected from the beginning, significant demand of activity in heating season from their side (eg. fuel uploading, ash downloading, chimney cleaning, etc). Burning almost 6 tons of oats demanded a lot of effort, power and they seemed not be ready for it. Finally they liked much more the other scenario where heat pumps were deployed and no manpower was demanded. The other problem occurred with the ventilation system. They have already used the HRS, and when it proved not to be efficient they were not happy to build another (ground) heat exchanger. Fortunately, it fitted in a basement of just raising garage. The garage was also used as a base for extra PV solar panels essential in the second scenario (Fig.2). Unfortunately, the two roofs (of building and garage) were together still too small to hold all necessary PV arrays. Some extra ground had to be deployed for that purpose what was a surprise for residents. The problem was that initially PV modules of $360 \mathrm{Wp}$ were designed for the project, but due to overall costs they were reduced to $280-320 \mathrm{Wp}$ power each, so the amount of them increased significantly (only 2 pcs of $360 \mathrm{Wp}$ were deployed on a tracker). Finally some $36 \mathrm{PV}$ modules instead of 28 initially designed were installed.

\subsubsection{The snow and cooling problem of PV modules}

Also formerly widely used ST (solar thermal panels) in this house seemed not to deliver as much energy as they were expected in wintertime (due to the snow, see Fig3), and the problem concerned also PV modules. To overcome the problem the new version of PVT was designed and tested in this project (patent pending). The cooling part of PV modules was used in winter to warm them up and get rid of snow layers (first right at Fig 4).

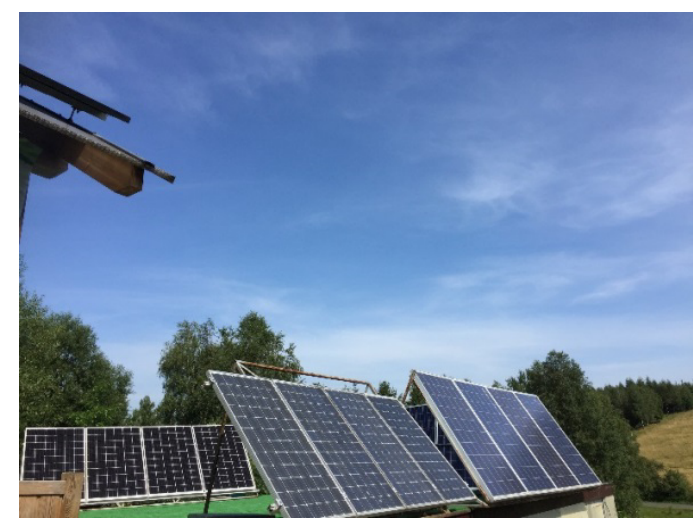

Fig 5. The PV arrays standing on the ground and the top of garage.

\subsubsection{The residents fromer habits problem}

One of the most interesting results of the second stage of the experiment was the diagnosed problem of necessary changes in residents habits in order to meet the nZEB 
state. As the energy demand was constnlty measured and displayed (by Unihome®BMS), it appears that "regular" habbits of some residents (like heavy use of hot water) have to be changed. This was difficult, but widely discussed was corrected in the second Variant by the residents themselves. As the family liked very much the idea of fully energy independence and zero emmisions they have adopted to the new conditions of hot water usage. Surprisingly enough the disc washing habits have to be adjusted. Finally a compromise of exchanging the disc washer to new model with much less energy and water demand solved the problem. Also some changes in heating habits and cooling habits have to be introduced. Resistance from window opening as well as better temperature adjustment (individual for every room) solved the problem at stage two.

\section{Summary}

To sum up, the performed 24 months test showed potential in both bio and PV technologies as possible retrofitting scenarios of existing houses into nZEB's in Poland. The test found important limitations and preferences of such refurbishing, mainly related to human beings living in such a building. Some economic calculations performed show that not the investment cost but LCC should be considered as real cost in such a retrofit. Finally the solution based on improvement of insulation of the building envelope, ventilation retrofiting system and introduction of HP's as main source of heat and cool energized from locally harnessed solar energy (PV and PVT) proved to be the optimal solution. Nevertheless the achievement of nZEB state was possible only thanks to possibility of relatively cheap energy storage in the national grid.

\section{References}

1. Finansowanie poprawy efektywności energetycznej budynków w Polsce Report Buildings Performance Institute Europe (BPIE) www.bpie.eu 2016

2. J. Biskupski, Techniczne, ekonomiczne $i$ środowiskowe aspekty zastosowania OZE w budynkach mieszkanych $w$ Polsce (PhD Thesis Politechnika Krakowska 2018)

3. Ustawa o OZE - tekst jednolity z lipca 2018 https://narodowyprogram.pl/oze/ustawa-oze-2018

4. Raprot PV in Poland: posted on a web site: http://polskapv.pl/polski-rynek-fotowoltaiczny-wliczbach-stan-na-31-grudnia-2017r/

5. EN 15603:2013, "European Standard: draft Overarching standard EPBD," CEN (European Committee for Standardization), Avenue Marnix 17, B-1000 Brussels, 2013.

6. I. Sartori, Methodology for optimal energy system design of Zero Energy Buildings using mixedinteger linear programming, Elsvier 2016. 